O'DWYER, J. M. (1999) Psychiatric training of preregistration house officers, Psychiatric Bulletin, 23, $283-285$

Rebecca Mason Consultant Child \& Adolescent Psychiatrist, The Specialist Child \& Adolescent Mental Health Services, Beck House, 3 West Parade Road ScarboroughY012 5ED

\section{Classification under Mental Health Act 1983 and consent to treatment}

A ruling was recently passed in the Court of Appeal, and this judgment is likely to have a significant bearing on psychiatrists working with patients detained under the category of mental impairment and psychopathic disorder.

The Court was hearing an appeal against the decision of the high court about ' $B$ ', an in-patient at Ashworth hospital. B had been detained under a restriction order under the category of mental illness. The responsible medical officer had recommended to the Mental Health Review Tribunal (MHRT) that B suffers from a mental illness as well as a personality disorder. The MHRT chose not to reclassify $B$ under the category of psychopathic disorder.

$B$ was subsequently transferred to a ward in the personality disorder unit and B sought a judicial review claiming that he should not be treated for psychopathic disorder because he was not detained under that category. The high court dismissed the application and B's solicitors appealed against the decision.

The Court of Appeal heard the case in April 2003 and ruled that compulsory treatment could be given only for the mental disorder for which the patient has been detained.

Patients detained under the category of mental impairment and psychopathic disorder often have comorbid mental illnesses which may not be severe enough to warrant detention on their own accord. These patients often receive treatment for the mental illness even though they are not classified as having mental illness under the Act.

As a result of the ruling of the Court of Appeal, it will become necessary to reclassify all such patients under the additional category of mental illness, unless it can be established that psychotropic medication is being administered exclusively for the treatment of mental impairment or psychopathic disorder.

This is likely to present problems for patients who are under restriction orders because the RMO does not have the power to reclassify them and would need to wait for a tribunal to do the reclassification. If the tribunal chooses not to reclassify, it might become difficult to justify administration of psychotropic drugs to these patients.

It would be interesting to see if Ashworth Health Authority chooses to take the case to the House of Lords.

$R(B)$ v. Ashworth Health Authority (2003) EWCA Civ 547 http://www.courtservice.gov.uk/

Judgments.do

Prabhat Mahapatra Consultant Psychiatrist, Care Principles, Dover Road, Barham, Canterbury CT4 6PW. Email: pk.m@ntlworld.com

\section{Trainees' experiences of a Balint group}

Many thanks to Das et al (Psychiatric Bulletin, July 2003, 27, 274-275) for sharing their experiences of Balint group. We are fortunate to have a well structured local Balint group led by a psychotherapist, based on the Model of Transactional Analysis. Being honest, we started to attend the groups because it was mandatory and once we developed the necessary mindset, we found the sessions palatable, with an ability to reflect and ventilate our true feelings.

This has led to better understanding of interpersonal interactions across patients, families, staff and colleagues. No doubt our attitudes towards difficult patients and staff members has changed. Meeting regularly has promoted team bonding and has alleviated the distress of on call hours.

Balint groups must be identified as an essential component of psychiatric training. Despite Psychotherapy training being mandatory, very little has been done to implement these regulations locally.

M. Krishna Senior House Officer, 50 Trefoil Close Huntington, Cheshire, V. Veramacheneni West Cheshire Hospital

\section{Advocacy in practice}

I am writing on behalf of the Advocacy Working Party of the Royal College of Psychiatrists, which has been charged with the responsibility of updating the Council Report on Advocacy published in 1999.

Advocates working on behalf of patients are going to become a more regular feature of our working lives and we intend to produce a document that reflects real experiences, as well as idea practice. To this end, we would like to invite any member of the College to write to us about their experience, both good, bad and indifferent, of advocacy in practice.

This would help up to formulate a realistic account of present practice, in the proposed chapter on the role and responsibilities of the psychiatrists and advocates.

Tom Harrison Co-chair, AdvocacyWorking Group, Scarborough House, 35 Auckland Road, Birmingham B11 1RH

\section{In defence of inquiry panels}

As a colleague who has also protested about the iniquities of inquiries (Lowe, 1996), I am heartened by Mark Salter's latest contribution to the debate (Salter, Psychiatric Bulletin, July 2003, 27, $245-$ 247). A patient of mine was convicted of manslaughter and, although the internal inquiry exonerated the clinical team, an external inquiry serves other purposes very well rehearsed by Salter. It is desirable, however, to expect inquiry panel members (including non-psychiatrists) to accept clear boundaries, realistic terms of reference, to be inducted for the purpose, and to function as openly as possible. Panel members are learning progressively from their predecessors and do not have to accept a process that is irrational. Reports, unique in their individuality, include detailed psychiatric case histories from which clinical lessons can be drawn - though not necessarily fulfilling public expectations. More could be done to disseminate this knowledge officially (King, 2000)

The effects of inquiries are unpredictable but may lead to significant changes. The Clunis Inquiry heralded the introduction of supervised discharge orders (1996). Consultants invited to sit as inquiry panel members should be drawn from the likes of Dr Salter and not held in contempt by their colleagues (Veasey \& Cox, 2000) for participating.

From April 2004, responsibility for independent reviews passes to the new Commission for Healthcare, Audit and Inspection (CHAl) and the Government would like to see a national specification for training in complaints investigation (Department of Health, 2003). The College should lobby to ensure that homicide inquiries are included in CHAl's remit. Contributions from past panel members and critics would help in formulating an appropriate training programme for psychiatrists and lay colleagues.

DEPARTMENT OF HEALTH (2003) NHS complaints reform - Making things right. London: DoH.

KING J. R. (2000) Homicide is impossible to predict. Psychiatric Bulletin, 24, 152

SALTER, M. (2000) Serious Incident Inquiries have a role. Psychiatric Bulletin, 24, 196.

- (2003) Serious Incident Inquiries: A Survival Kit for Psychiatrists. Psychiatric Bulletin, 27, 245-247.

VEASEY, D. \& COX, J. L. (2000) Further comments on inquiry panels. Psychiatric Bulletin, 24, 393-394.

M. R. Lowe Consultant Psychiatrist, Basildon Hospital, Nethermayne, Basildon, Essex SS16 5NL 